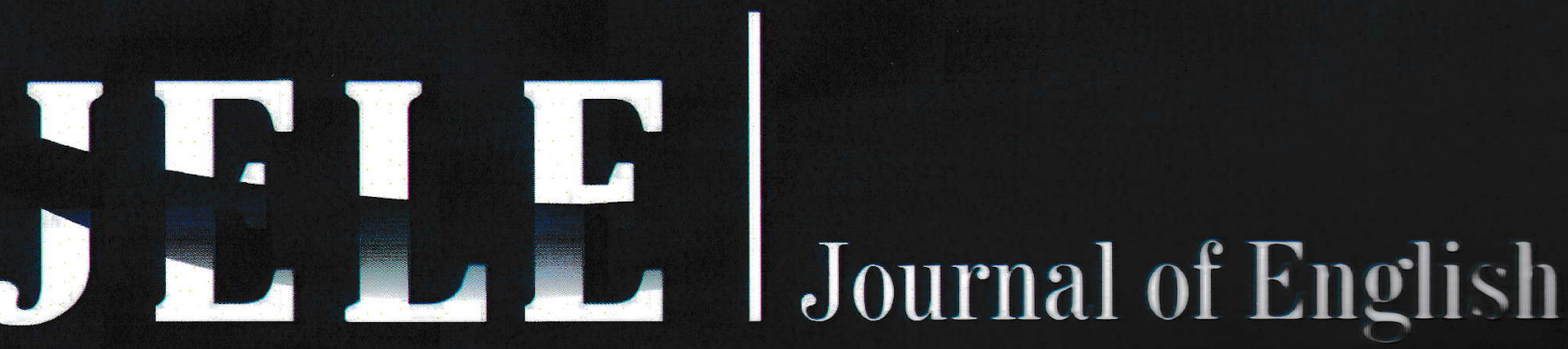 Language and Education
}

English Education Study Program Faculty of Teachers Training and Education Mercu Buana University of Yogyakarta 


\title{
Developing an Electronic Dictionary of Elements and Compounds in Chemistry to Improve the Tenth Graders' Pronunciation
}

\author{
Mat Ibnu \\ State Senior High School 2 Semarang \\ Email : ibnoe104@yahoo.com
}

\begin{abstract}
Inaccessibility of electronic dictionaries for learning pronunciation of elements and compounds in Chemistry was found at Semarang State Senior High School 2. The observed inaccessibility came from the Chemistry teacher who shared her problems that her students got difficulties in pronouncing elements and compounds. Then, the existing electronic dictionaries were lack of the words they needed. Hence, this study would like to develop an Electronic Dictionary of Elements and Compounds in Chemistry (EDECC) for assisting students, notably the tenth graders of Semarang State Senior High School 2, to improve their pronunciation in learning elements and compounds. This study employed Research and Development design to develop the EDECC. This design was adopted and modified fromBorg and Gall (2003:772). Seven stages were employed for developing EDECC were information and research collecting, planning, developing, validating, revising, try out, and producing final EDECC. Observation, interview, validation, and pre-test also post-test were administered to collect the data while both quantitative and qualitative approaches were used to analyze the collected data. From the result of observations, questionnaires, validation, interviews, and pre-test and post-testwere found that applying the EDECC gained positive perspectives toward teaching and learning process.Moreover, the test of effectiveness consisting validity and reliability tests on pretest and posttest employing quasi experimental design reported that there was significant difference between the result of pretest and posttest. It means that all the result of collected data agreed that the EDECC could be implemented in improving the students' pronunciation.
\end{abstract}

Keywords : Electronic Dictionary, Teaching Pronunciation, Chemical Elements and Compounds

\section{INTRODUCTION}

English is as an instrument of applying science and technology in the present era to accelerate developmental process especially in education. Moreover, some schools in Indonesia applies English as Medium of Instruction (EMI) for some subjects, that is Sciences and
Mathematics. Semarang State Senior High School 2 has applied EMI since this school employed the Immersion Program from 2005-2009 and International Standardized School Program from 2009-2013. Even though, those programs were stopped by the government, applying EMI is still running in the school. Channa (2012) reveals his research that these 
students differed widely in their attitudes towards teachers' using EMI in the class and laboratories. They were positive about using English language, considered this as beneficial for students to develop their confidence and to comprehend scientific theories, logics, reasons and problems for playing their roles to participate actively in the classroom as well as outside of the class. Based on the previous observation, the students still have problems dealing with the pronunciation, especially when they are learning elements and compounds in Chemistry even though, EMI has been implemented for some years in Semarang State Senior High School 2. The students and their Chemistry teacher have tried to find out the existing dictionaries that can be used to assist them to solve their problems. They could not find the appropriate dictionaries that were in line with their needs that is the ones equipped with sounds. Actually, they could use google translation to help them get the pronunciation of elements and compounds. They just typed them and listened to their pronunciation. However, they did not have any internet access all the time. Based on the above reasons, the researcher developed an Electronic Dictionary of Elements and Compounds that could be installed in their computers or laptops and operated at any time they wanted.

Electronic dictionary electronic dictionary is not a machine readable version of conventional dictionaries. It is a completely new dictionary designed from scratch. It is a dictionary developed for a computer to understand a natural language, (Nessy, 2000). Electronic dictionary is very essential in learning a language. A good dictionary consists of the various parts of speech and it also acts as a reference for the purpose of an excellent and accurate language. The term electronic dictionary can be used to refer to any reference material stored in electronic form that gives information about spelling, meaning, or use of words. The learners can use the electronic dictionary to know the sound of words stored in its data base.

Electronic dictionaries can be classified in various types according to different criteria. Some researchers have attempted to devise typologies of electronic dictionaries. One example of an electronic dictionary typology 
is that by Pastor and Alcani (2009), which focuses on technical and meta(lexicographic) evaluation. Based on technical evaluation, they distinguish between online or offline dictionaries. Offline dictionaries comprise pocket electronic dictionaries (PEDs) and PC dictionaries. PC dictionaries include dictionaries in CD- ROM, floppy disk and other formats. Offline dictionaries generally provide more search techniques than online dictionaries, and are more stable and durable compared to online dictionaries. Online dictionaries are more accessible than the CD-ROM format, and most online dictionaries are free. They affirm that electronic dictionaries differ from paper dictionaries in factors such as use, presentation, search capabilities, technical aspects, and nature of contents (multimedia elements). One of the advantages of using electronic dictionaries is that it allows the user to make cross references without even moving away from the page that the user is viewing. This feature of immediate cross reference is not present in the paper dictionaries. The bilingual production dictionaries are few in numbers because a lot of storage space is required for accommodating this type of dictionary.

$$
\text { Mayer and Clark, (2008:35) }
$$
stated that multimedia which is commonly has multi representations which enter to students' senses through ears and eyes. students can see the words and pictures. Then, words are received by ears and pictures will be accepted by eyes. After the selecting process was done, those presented words and images are linked into the memory. The words and images that are selected become sounds and images. Then, the organizing process is also done to change the sounds become verbal model and images become pictorial model. After they were completed, the words and images integration happens in our memory. As a result, students got prior knowledge about what have been learnt through multimedia learning. The developed electronic dictionary employs the multimedia since it is equipped with words, sounds, and images in the hope that it can be used as medium to improve the students' ability, especially their pronunciation. 
Computer Assisted Language Learning is important in the area of language teaching and learning situation. Learning language, especially English, is general. In English as a Medium of Instruction, the language should be mastered together with the content of subject matters, (Chammot, 1986). Chemistry teachers try to maximize the opportunities offered by technological advances. Therefore, the teachers have to make the decision to use technology as a part of their language learning environments and ensure that they are familiar with the technological options available and their suitability to particular learning goals and thus implement these technologies capitalizing their specific features. The students need to be able to continuously use, experiment and evaluate appropriate and meaningful CALL activities to enhance English proficiency and master English language skills and the content of subject matters.

Thus, the Electronic dictionary of elements and compounds in Chemistry is one of the ways to develop teaching tools using modern technology that is multimedia and computer. The developed electronic dictionary of elements and compounds contains information that is necessary for the students to understand the English and Indonesian elements and compounds in Chemistry designed in employing multimedia and computer. Students get knowledge easily from the electronic dictionary such as: their formula, other names of compounds, overviews, and images. However, the most important thing that the researcher considers is the sound of the elements and compounds and their overviews. The students are able to learn their pronunciation through the developed dictionary.

According to Dalton and Seidlhoffer (1994) Pronunciation is a way how sounds are articulated by speakers marking their social class, education and so forth. Since sound is very important in making an understandable speech, the researcher assumes that it is very vital to teach the learners how to say words correctly. Pronunciation is also the aspect of language that is most difficult to acquire. Although some students with 'an ear for language' can 'pick up' pronunciation very effectively, for most they requires 
special training. Most students are highly aware of this and constantly request further tuition in pronunciation. Furthermore, the Chemistry teachers are forced to teach English in their content area. They find a lot of difficulties in pronouncing English words related to the subjects, especially elements and compounds. In addition, the students get some difficulties in learning how to pronounce them. Therefore, they need an appropriate tool that can used to solve their problem.

Teaching English for elements and compounds in Chemistry covers some important matters involving Chemistry curriculum syllabus, lesson plan, pronunciation for Chemistry, strategy to teach pronunciation for Chemistry, and Assessment. The researcher puts the curriculum as the basis of developing the Electronic Dictionary of Elements and Compounds in Chemistry. Based on the difficult way how to teach pronunciation for Chemistry, the Chemistry teachers should employ some strategies that can assist them to help their students understand the pronunciation of some words in Chemistry especially elements and compounds. Applying some strategies in teaching pronunciation of elements and compounds in Chemistry needs a medium that can assist them. The researcher develops it in order to cope the problem of the inaccessibility of the existing electronic dictionaries.

\section{METHODS}

\section{Research Design}

The researcher used research and development ( $\mathrm{R}$ and $\mathrm{D}$ or, more often $R \& D$ ) since the objective of the research is to develop electronic dictionary of elements and compounds in chemistry to foster students' pronunciation especially at Semarang State Senior High School 2. The process of this design can be defined as $\mathrm{R} \& \mathrm{D}$ cycle. As Borg and Gall (2003:772) noted down that this cycle employed observation the preliminary studies related to the developed product or materials, developing intended product, validating the developed product to some experts, and revising suggestions from expert, and trying out the product. 
Procedure of the Research and Development

The researcher applied the process of this design stated Borg and Gall (2003). In his model, Borg and Gall (2003) asserts seven stages of developing the product. They are as follows: (1) Research and Information Collecting was conducted through need analysis dealing with (a) the role of existing electronic dictionaries play in language learning, (b) the students' problems with English in learning sciences, especially Chemistry, (c) how much and how often the students used dictionaries, (d) how the students find what they needed in electronic dictionaries. (2) Planning consisting of finding out (a) the concept of developing the EDECC, (b) software used in that product, (c) the feasibility and acceptancefeasibility and acceptance of the product, (3) Developing preliminary form of product was conducted through (a) finding sources of elements and compounds, (b)Recording the materials (c) using Microsoft access 2007(4) Validating product was conducted by two experts of materials, one Chemistry teacher, and one multimedia expert, (5) Revising product was carried out after the experts had given their suggestions and comments, (6) Trying out product was conducted in the experimental group and giving pre test and post test for both the control and experimental groups. The result of trying out was analyzed, (7) Final product was finalized with two interface designs that were elements and compounds. Then, the fixed product development was ready to be demonstrated, published, and distributed to go to public..

\section{Trying out of Product}

1. Research Design of Try Out

The effectiveness of Electronic Dictionary of Chemical Elements and Compounds was measured by Pretest Posttest Quasi Experimental Designwhich employed pre-tests and post-tests for both experimental and control groups.

2. Population and Sample of the Study The try out research was conducted at the tenth graders of Semarang State Senior High School 2. It was located on J1. Sendangguwo Baru No. 1 Semarang. There were eleven classes at the tenth graders of natural science program (IPA) in the academic year 
2013/2014. For deciding the class of try out, the researcher employed Cluster Random Sampling technique for this issue. Cohen, Manion, and Morrison (2007: 115) noted down that each member of the population of this study had the chance equally to be selected as the sample or subject of the study. This study used a class as the unit of population.

\section{Procedures of Try Out}

The try out was organized on October $7^{\text {th }}, 2013$. The pre test was given to control and experimental groups. Then, the treatment was conducted in the experimental group on October $9^{\text {th }}$, 2013. Finally, The post test was carried out in both the control and the experimental groups on October $14^{\text {th }}$, 2013.

\section{Instruments and Data Collection Techniques}

The instruments and data collection techniques were as follows: the first was questionnaires. The researcher distributed the questionnaires to the Chemistry teachers and students to get the data. It consisted of eight questions with five multiple choices covering a, $\mathrm{b}, \mathrm{c}, \mathrm{d}$, and e options. The questions dealt with the practicality, the attractiveness, the usage possibility in teaching and learning process, the easiness in operating, the appropriateness, the pronunciation existence, the helpfulness, and the clarity. The second was observation. Hyland (2003) states that observation methods attempt to bridge this gap by systematic documentation and reflection of participants. For doing observation how the Chemistry teacher used the product, the researcher employed observation checklist involving six aspects. Those were 1) The teacher explained how to operate an Electronic Dictionary of Elements and Compounds in Chemistry (EDECC); 2) The teacher demonstrated how to use the EDECC., 3) The teacher gave the students some training to operate the EDECC; 4) The teacher gave the students some exercises to operate the EDECC; 5) The teacher gave an opportunity to students to ask some difficulties in operating the EDECC; 6) The teacher gave some assessments to students how to pronounce elements and compounds in Chemistry by using the EDECC. The third was interview. It was a flexible tool for data collection, enabling multi-sensory channels to be 
used: verbal, non-verbal, spoken, and heard (Cohen, Manion, Morrison, 2007:397). This study administered structured interview and the interviewee were Chemistry teacher and some students of grade ten of Semarang State Senior High School 2 that belonged to the experimental group. The forth was teachers' and experts validation. This Validation was distributed on the Chemistry teacher, an expert of material development and an expert of multimedia development. The experts and teacher were requested to give a thick on the checklist on all aspects which are corroborated. Those aspects cover Data Base Design Program, Friendly User Principles, The Material Appropriateness, The Program Usage, and The Usage Technique, The Sound Usage. The last was Pre-test and Posttest. The pre-test and post-test were conducted for the control and experimental groups.

\section{Techniques of Analyzing the Data}

The data collection such as comments, suggestions, and observation results during the try out were qualitatively analyzed. They were added as an input to revise the developed product. In addition, the numeral data taken from the experts' ideas, the Chemistry teacher, and students were quantitatively analyzed with percentage and categorization techniques.

The data of questionnaires provided by the Chemistry teacher and students were classified into two categories. The first was considered to be positive side consisting of the options of (a) representing 'very practical', 'very attractive', 'very possible to use', 'very easy to operate', 'very fulfilled', 'very completed', 'very helpful', and 'very clear, (b) representing 'practical', 'attractive', 'possible to use', 'easy to operate', 'fulfilled', 'completed', 'helpful' and 'clear' and (c) representing 'practical enough', 'attractive enough', ' possible enough to use', 'easy enough to operate', 'fulfilled enough', 'completed enough' 'helpful enough', and 'clear enough' while the options of (d)meaning 'not practical', 'unattractive', 'impossible to use' 'uneasy to operate', 'not fulfilled', not completed', 'helpless' and ' unclear' and (e) meaning 'very unpractical', 'very unattractive', 'very impossible to use', 'very uneasy to 
operate', 'very unfulfilled', 'not completed at all', 'very helpless', and 'very unclear' belong to negative one. The collected data were calculated by the formula of percentage. The percentage of the quantitative data of the observation was converted into qualitative data based on the score conversion reference stated by Bloom, Madaus \& Hastings (Tanwey Gerson Ratumanan \& Theresia Laurens, 2003: 19) as it was showed on table 1.

Table 1. Percentage of Learners' Observation was Converted into Qualitative Data

\begin{tabular}{cc}
\hline Percentage $(\%)$ & Criteria \\
\hline $90 \leq X$ & Very good \\
$80 \leq X<90$ & Good \\
$70 \leq X<80$ & Good enough \\
$60 \leq X<70$ & Bad \\
$X<60$ & Very bad \\
\hline
\end{tabular}

The data of observation of how the teacher used the developed electronic dictionary in teaching and learning were classified into 4 representing 'excellent', 3 indicating 'above average', 2 denoting 'average', 1 meaning 'unsatisfactory', and 0 meaning 'not applicable'. Furthermore, the collected data of observation was descriptively analyzed using table of conversion and the table 1 .

The data of learners' observation in teaching and learning were classified into A: Learners' activeness in learning process, B: Enjoyment in learning, C: Eagerness to do all. Then, the percentage of the quantitative data of interview was converted into qualitative data based on the score conversion reference stated by Bloom, Madaus \& Hastings (Tanwey Gerson Ratumanan \& Theresia Laurens, 2003: 19). It was stated on the table 1.

Then, the researcher both calculated the score of each point criteria from experts and teachers consisting of Program Data-Base Design, User-Friendly Principles, Suit to Materials, The program use, The technique use and The Sound Usage. The formula was as follows: 


$$
\text { Average score of each criteria }=\frac{\text { Score }}{\text { Max score }} \times 100 \%
$$

The researcher calculated the average validation form. See the example score of each criterion on the below: Mean or average score $=$

Adding percentage of each criterion from experts and teachers Number of expert and teachers

The percentage of the quantitative data of the material expert, a Chemistry teacher, and a Multimedia expert was converted into qualitative data based on the score conversion reference stated by Bloom, Madaus \& Hastings (Tanwey Gerson Ratumanan \& Theresia Laurens, 2003: 19) as it was showed on table 2.

At last, the researcher calculated the score of pre and post test of the control and experimental groups. The first step was finding the descriptive statistics of the pre test and post test of the control group. Employing data analysis of Microsoft Excel, the researcher got the mean, median, mode, and standard deviation of pre test and post test of the control group. The second, those data were calculated to get the t-Test (dependent). The result of t-Test (dependent) was compared with the score of t-Table (distribution) for significant level 5\%.
If the result of $\mathrm{t}$-Test (dependent) was lower than the result of t-Table (distribution). It meant that there was no significant difference between pre and post-test. If the result of t-Test (dependent) was higher than the result of t-Table (distribution), it could be considered that there was significant difference between pre and post-test. The researcher did the same steps to the experimental groups. Then, the researcher also compared the scores of post test of the control group with the score of post test of the experimental group. He got each mean and standard deviation of each group. After that, he calculated the value t-Test which was compared with the t-Table (distribution) for significant level 5\% and $1 \%$. If the value t-Test (distribution) were lower than the value t-Table (distribution) for significant level $5 \%$ and $1 \%$, it would be considered as no significant 
difference between the post test of the control and experimental groups. On the other hand, if the value t-Test (distribution) were higher than the value t-Table (distribution) for significant level $5 \%$ and $1 \%$, it would be meant that there was significant difference between the post test of the control and experimental groups. They could be shown on the following formula: a) significant difference; $\mathrm{t}$ Table (distribution) in the level of $5 \%$ $<\mathrm{t}$-Test $>\mathrm{t}$-Table (distribution) in the level of $1 \%$, b) no significant difference; ; t-Table (distribution) in the level of $5 \%>\mathrm{t}$-Test <t-Table (distribution) in the level of $1 \%$.

\section{FINDINGS AND DISCUSSION}

The result of questionnaires provided by the Chemistry teacher and students could be calculated that options of (a) representing 'very practical', 'very attractive', 'very possible to use', 'very easy to operate', 'very fulfilled', 'very completed', 'very helpful', and 'very clear, (b) representing 'practical', 'attractive', 'possible to use', 'easy to operate', 'fulfilled', 'completed', 'helpful' and 'clear' and (c) representing 'practical enough', 'attractive enough', ' possible enough to use', 'easy enough to operate', 'fulfilled enough', 'completed enough' 'helpful enough', and 'clear enough' got 291 of total 299 options. Therefore, the percentage of positive views of the Electronic Dictionary of Elements and Compounds in Chemistry (EDECC) was $\mathbf{9 7 . 3 2 \%}$. On the other hand, the options of (d) meaning 'not practical', 'unattractive', 'impossible to use' 'uneasy to operate', 'not fulfilled', not completed', 'helpless' and ' unclear' and (e) meaning 'very unpractical', 'very unattractive', 'very impossible to use', 'very uneasy to operate', 'very unfulfilled', 'not completed at all', 'very helpless', and 'very unclear' got 8 of total 299 options. Thus, the percentage of negative views of the EDECC was $\mathbf{2 . 6 8 \%}$. It could be concluded that the EDECC had positive views for the Chemistry teacher and students.

The total scores of observation result of how the Chemistry teacher used the developed electronic dictionary in teaching and learning was 22 and the maximum score was 24. Then, the total score was divided 
by the maximum score. The result of division was multiplied by $100 \%$. Thus, the result was $\mathbf{9 1 . 6 7 \%}$. Based on the percentage conversion as stated on table 1 , the observation result of how the teacher used the EDECC was very good. Therefore, how the teacher used the EDECC in the classroom had good effects for students to strengthen their ability to use it.

The result of learners' observation was classified into A: Learners' activeness in learning process, B: Enjoyment in learning, C: Eagerness to do all. The percentage of activeness in learning process was $\mathbf{8 6 . 1 1 \%}$. The percentage of enjoyment in learning was $\mathbf{8 8 . 8 9 \%}$. And the percentage of Eager to do all got $\mathbf{8 3 . 3 3 \%}$. According to the percentage result of each aspect of learners' observation, it could be concluded that the learners' activeness in learning process, enjoyment in learning, and Eagerness to do all were good.

The result of the average score of experts' and teacher's validation were classified into: 1) Design of Data Base Program got $\mathbf{9 7 . 9 2 \% , 2 ) ~ F r i e n d l y ~}$ user aspect got 98.22\%. 3) Material Appropriateness got $\mathbf{9 7 . 9 2 \% . ~ 4 ) ~}$ Program usage got $\mathbf{9 8 . 4 4 \% . ~ 5 ) ~}$ Technical usage got $\mathbf{9 8 . 4 4 \%}$. Thus, based on the collected data, it could be concluded that the EDECC was very good and could be implemented in teaching pronunciation of elements and compounds in Chemistry.

The result of pretest and posttest of the control group was as follows:

Table 3. The Calculation of Pre test and Post test of the Control Group

\begin{tabular}{ccccccc}
\hline Activities & N & Mean & $\begin{array}{c}\text { Standard } \\
\text { Deviation }\end{array}$ & t-Test & df & t Table 5\% \\
\hline Pre test & 34 & 3.04 & 1.51 & \multirow{2}{*}{1.48} & 66 & 1.697 \\
\hline Post test & 34 & 3.57 & 1.45 & & & \\
\hline
\end{tabular}

Based on the above calculation, it showed that $\mathrm{t}$-Test was 1.48 while $\mathrm{t}$ Table was 1.697. Therefore, the value of $\mathrm{t}$-Test got lower than the value of $\mathrm{t}$ Table. Thus, it could be said that there was no significant difference between pre and post-test.

The result of calculation Pre test and Post test of the Experimental Group was as follows: 
Table 3. The Calculation of Pre test and Post test of the Experimental Group

\begin{tabular}{ccccccc}
\hline Activities & N & Mean & $\begin{array}{c}\text { Standard } \\
\text { Deviation }\end{array}$ & t-Test & df & t Table 5\% \\
\hline Pre test & 36 & 2.32 & 0.8 & \multirow{2}{*}{27.45} & 70 & 1.684 \\
\hline Post test & 36 & 7.92 & 0.92 & & & \\
\hline
\end{tabular}

Based on the above calculation, it showed that $\mathrm{t}$-Test was 27.45 while $\mathrm{t}$ Table (distribution) was 1.684 . Therefore, the value of t-Test got higher than the value of $t$ Table (distribution). Thus, it could be said that there was significant difference between pre and post-test. It meant the treatment had very good achievement in teaching and learning process in the experimental group.

Finally, the scores of post test of control group was compared with the score of post test of experimental group. The result of the calculation is as follows:

Table 4. The Calculation of Post test of the Control Group and Post test of the Experimental Group

\begin{tabular}{|c|c|c|c|c|c|c|c|}
\hline Groups & $\mathbf{N}$ & Mean & $\begin{array}{l}\text { Standard } \\
\text { Deviation }\end{array}$ & t-Test & df & $\begin{array}{c}\text { Table } \\
5 \%\end{array}$ & $\begin{array}{c}\text { t Table } \\
1 \%\end{array}$ \\
\hline Control Group & 34 & 3.57 & 1.45 & \multirow[b]{2}{*}{15.07} & \multirow[b]{2}{*}{68} & \multirow[b]{2}{*}{1.671} & \multirow[b]{2}{*}{2.390} \\
\hline $\begin{array}{l}\text { Experimental } \\
\text { Group }\end{array}$ & 36 & 7.92 & 0.92 & & & & \\
\hline
\end{tabular}

Based on the above table, the post test was employed to the control group consisting of number of samples 34 . The post test of the control group achieved the mean of 3.57 , standard deviation of 1.45 . On the other hand, the post test was given to the experimental group consisting of number of samples 36, then, the result was the mean of 7.92 and standard deviation of 0.92 . After both of data were calculated, the value $\mathrm{t}$ Test was
15.07. Then, the value of t-test was matched with table $\mathrm{t}$ with significant level 0.05 and 0.01 with freedom degree of 68 . The result reported that t- Table (distribution) has to 1.697 for significant level 0.05 and 2.390 significant level 0.01. It was concluded that the value of t-Test was more than the value of t-Table (distribution) with significant level 0.05 and 0.01 . Thus, it could be said that there was significant difference 
between post test of the control group and the post-test of experimental group. Thus, the Electronic Dictionary of Elements and Compounds in Chemistry (EDECC) is an effective medium to improve the students' pronunciation skill, especially in pronouncing those words.

\section{CONCLUSION}

Firstly, the Electronic Dictionary of Elements and Compounds in Chemistry (EDECC) is equipped with sound effects therefore it can be used to assist the students of grade ten of Semarang State Senior High School 2 to learn pronunciation of the elements and compounds in Chemistry. In addition the electronic dictionary is completed with elements and compounds' formula, other English names, overviews, and images of their molecules. The students do need such an electronic dictionary.

Secondly, the researcher developed the Electronic Dictionary of Elements and Compounds in Chemistry (EDECC), there were some stages which were proposed by Borg and Gall (2003). The first stage dealt with starting to organize an observation at school to do need analysis and determine what media were developed. Then, he planned and developed the intended product that is the Electronic Dictionary of Elements and Compounds in Chemistry (EDECC). Afterward, validating also was done of some experts to know the feasibility of product that had been developed. Moreover, revising the developed product was employed to correct the previous suggestions and corrections from experts. Next, trying the product out was the following step in this study. At last, the final product was ready to be published.

Thirdly, based on the result of observations, interviews, questionnaires, pre-test, post-test, the Electronic Dictionary of Elements and Compounds in Chemistry (EDECC) can be applied to foster the students' skills in pronouncing elements and compounds in Chemistry. For this case is the tenth grader of Semarang State Senior High School 2. Moreover, the test of effectiveness by using pre test and post-test quasi experimental design reported that there was significant difference between the result of pre-test and post-test. It 
means that all the result of collected data agreed that the Electronic Dictionary of Elements and Compounds in Chemistry (EDECC) can be implemented for fostering the students' skills in pronouncing elements and compound in Chemistry.

It is finally suggested that in the future, there will be other researchers who develop other electronic dictionaries completed with the pronunciation sounds to practice and enrich the students' English skills. Based on the results of this research, it can be seen that the application of electronic dictionary is beneficial for the students. It suits best for the students' need. It would be better if there are other developments of English electronic dictionaries for all grades in all content subjects that use English as the medium of instruction.

\section{REFERENCES}

Borg, W. and Gall, M. (2003). Educational Research: An Introduction. $7^{\text {th }}$ edition. New York: Longman.
Brown, H. D. (2001). Principles of Language Teaching and Learning. New York: Pearson Education

Chamot A.U. and M.J. O’Malley (1986). A cognitive academic language learning approach: An ESL-content based curriculum. Rosslyn, VA: National Clearinghouse for Bilingual Education.

Channa, M. A., (2012). Teachers' Perceptions towards English Language as Medium of Instruction in Pakistan. Interdisciplinary Journal of Contemporary Research in Business, Volume 4, No 5, September 2012, available online at www.journalarchieves23.webs.com, accessed on March 1, 2013.

Cohen, L., Manion, L. and Morrison, K. (2007). Research Method in Education. Newyork: Routledge. 
Dalton, C. and Seidlhofer, B. (1994).

Sukardjo. (2005). Evaluasi Pronunciation. Oxford: pembelajaran. Diktat mata Oxford University Press. kuliah evaluasi pembelajaran. Hyland, K. (2003). Second Language Writing. Cambridge: Prodi TP PPs UNY. Tidak Cambridge University Press.

Mayer, R. E., \& Clark, R.C. (2008). ELearning and the Science of Instruction:Proven Guidelines for Consumers and designers of Multimedia Learning. San Fransisco: Pfeiffer

Nesi, H. (2000). The Use and Abuse of EFL Dictionaries. How Learners of English as a Foreign Language Read and Interpret Dictionary Entries. Lexicographica. Series Maior 98. Tübingen: Max Niemeyer.

Pastor, V and Alcina, (2009). Search Techniques in Electronic Dictionaries: A Classification for Translators. The ONTODIC Project: Methodology and Techniques for the Elaboration of Collocation Dictionaries Based on Ontologies, TIN2009-07690 


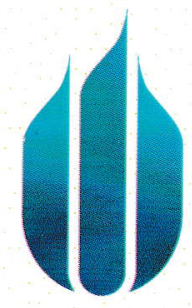

U N I VER S I TAS

MERCU BUANA

Y O G Y A K A R T A

ENGLISH EDUCATION STUDY PROGRAM

Faculty of Teachers Training and Education

Mercu Buana University of Yogyakarta

J. Wates Km. 10 Yogyakarta 55753 | jurnal.umby@gmail.com

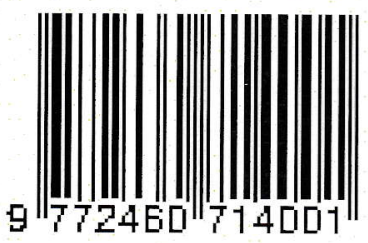

